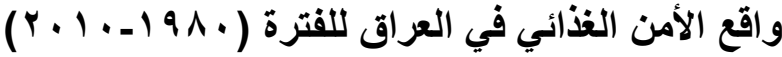

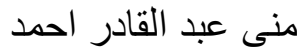
سالم محمد صالح

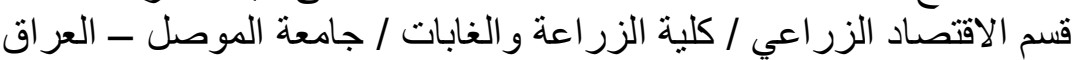

Muna_agriculture@yahoo.com

SALIMS1956@yahoo.com

\section{الخلاصة}

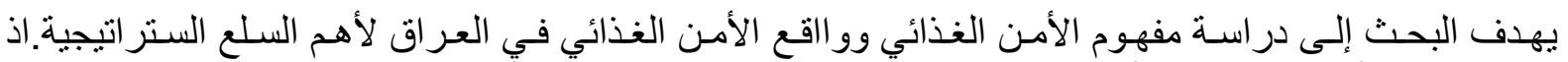

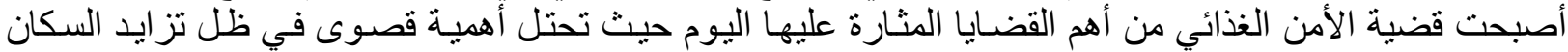

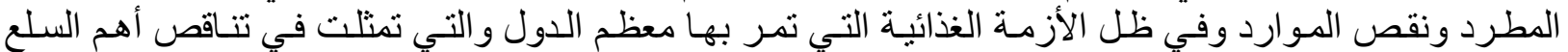

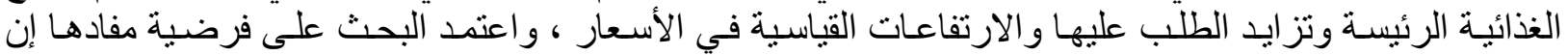

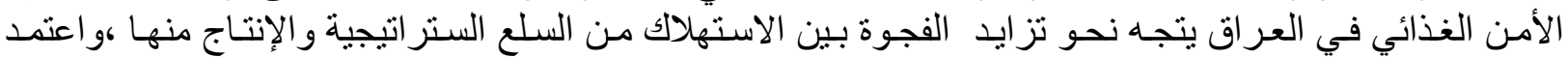

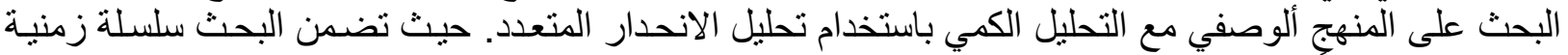

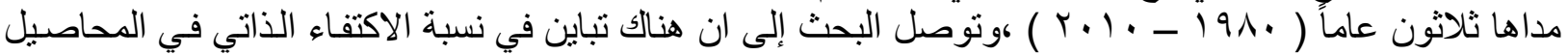

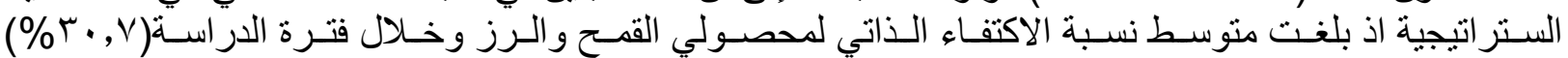

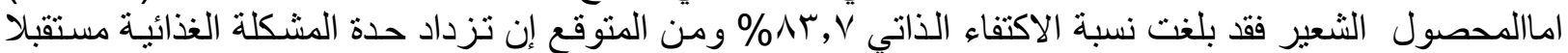

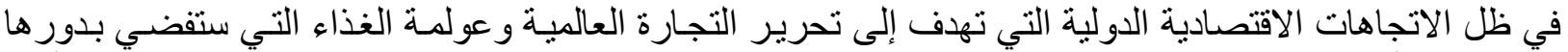

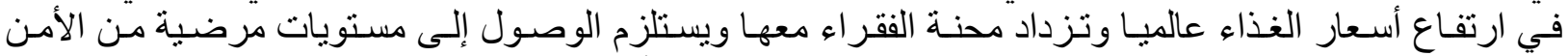

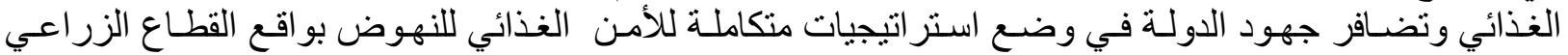

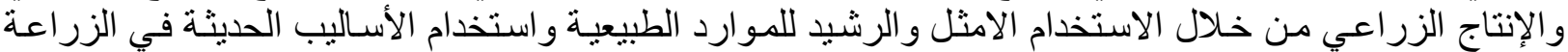

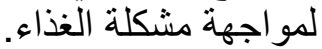

\section{المقدمة}

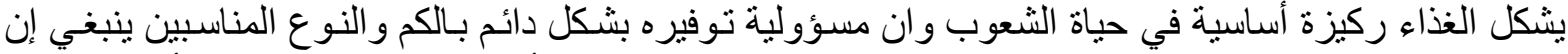

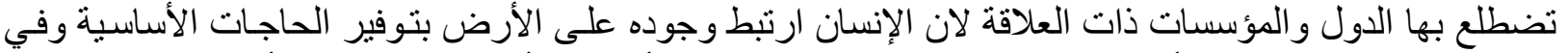

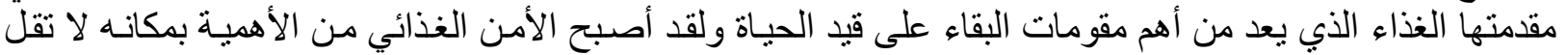

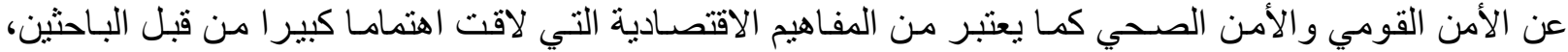

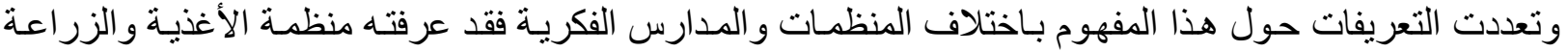

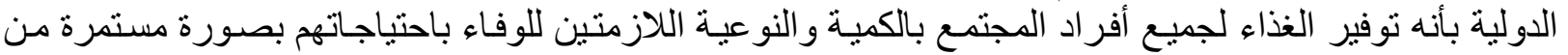

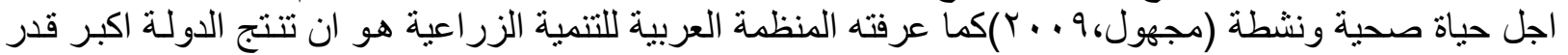

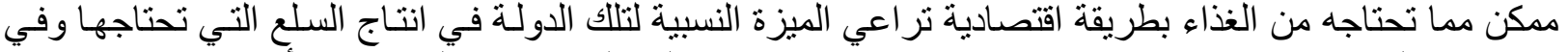

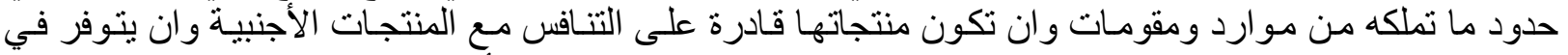

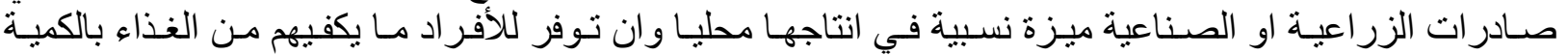

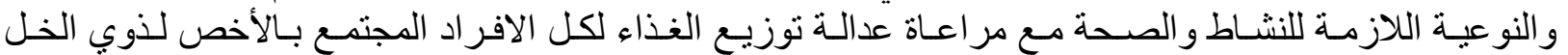

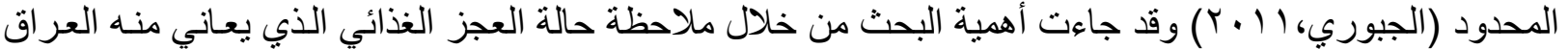

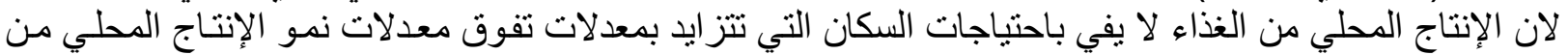

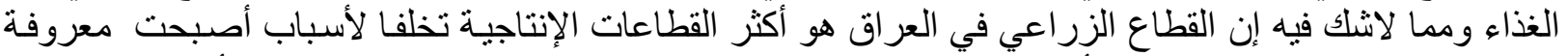

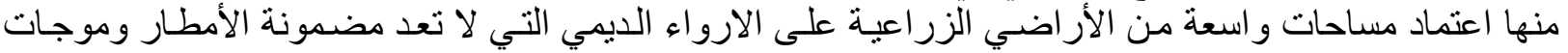

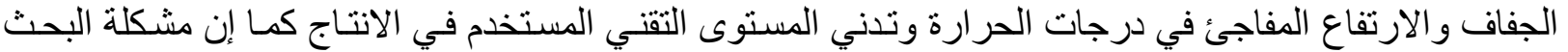

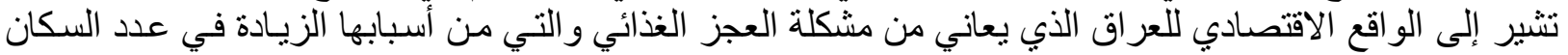

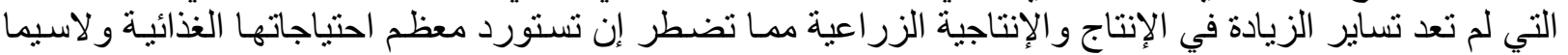

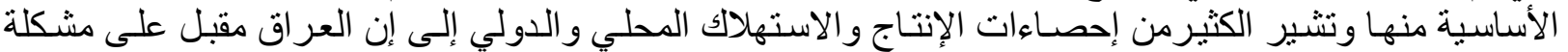

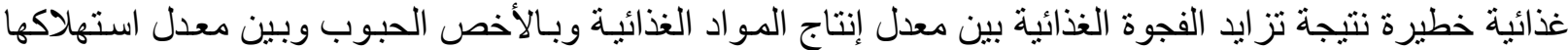

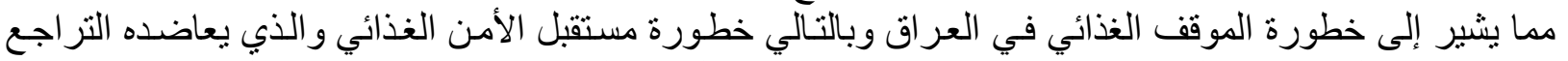

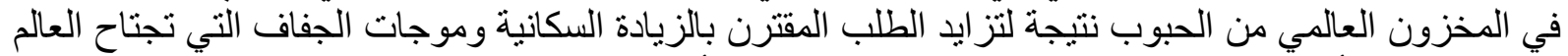

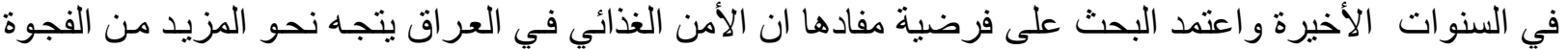

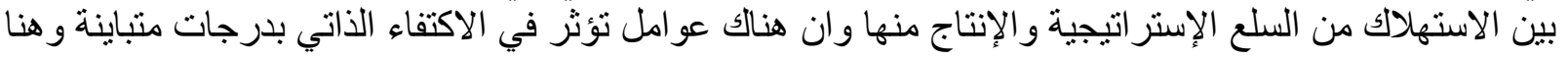




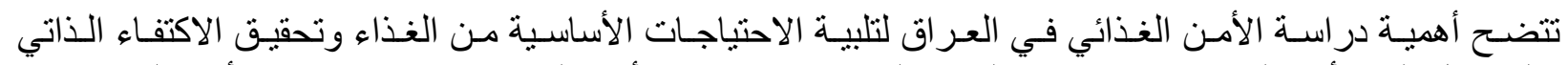

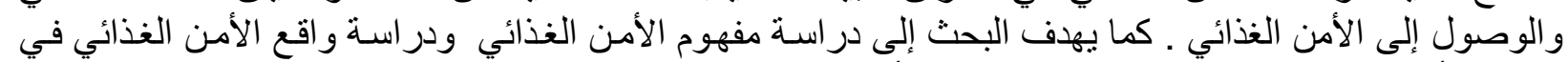

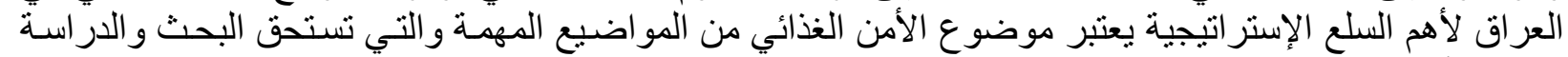

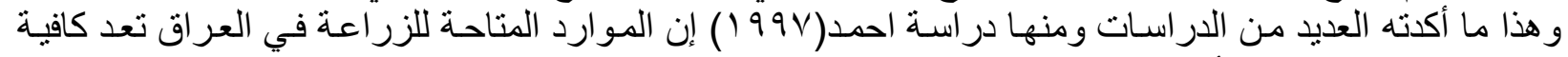

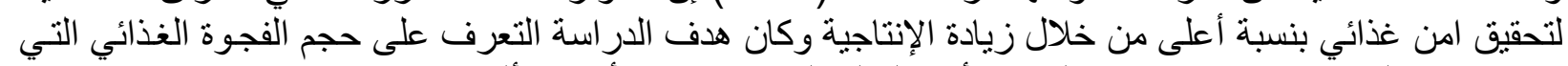

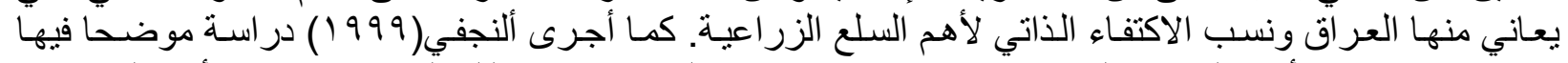

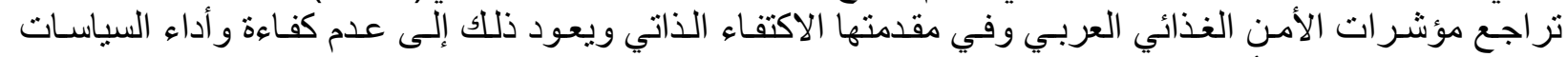

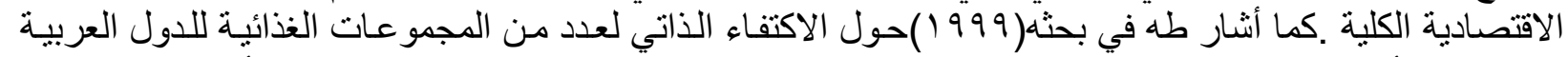

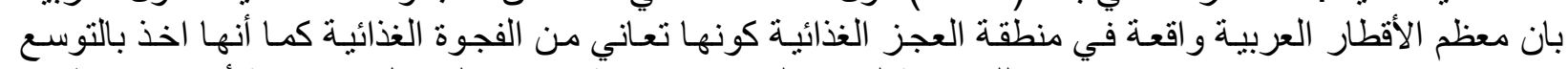

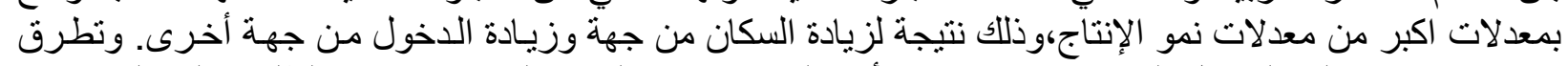

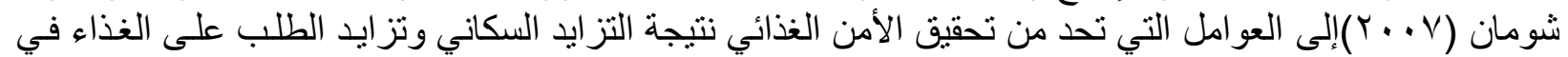

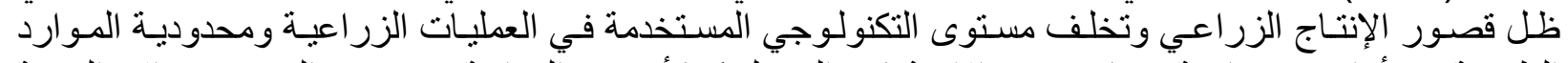

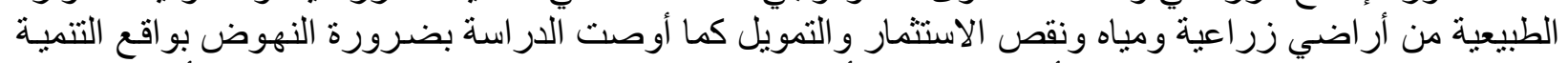

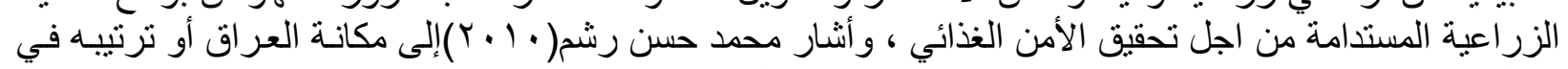

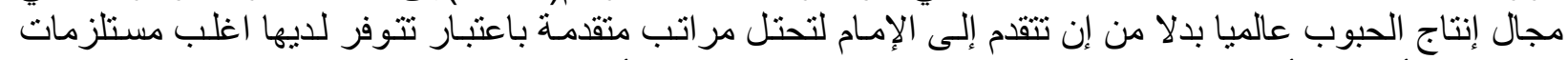

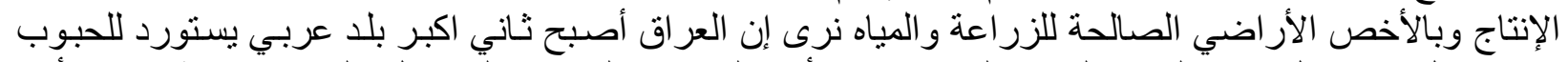

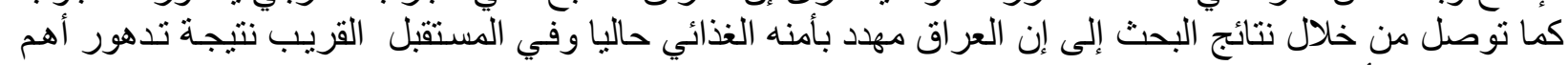

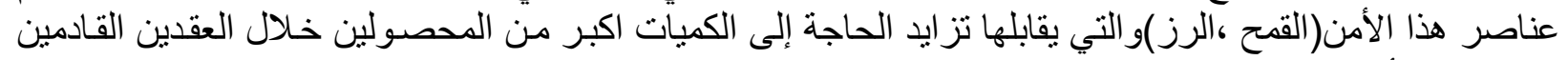

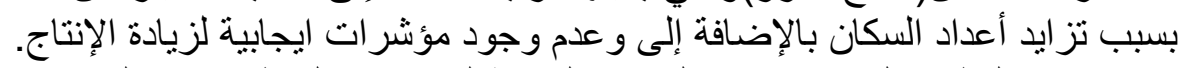

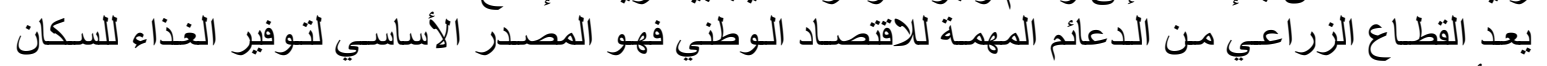

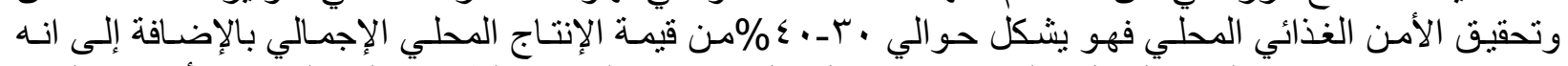

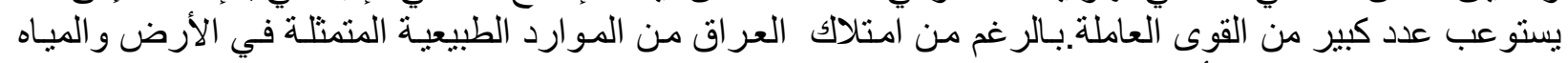

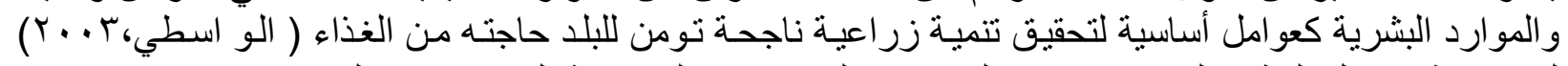

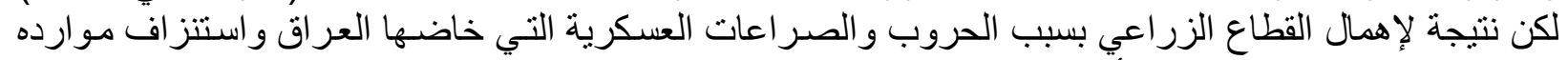

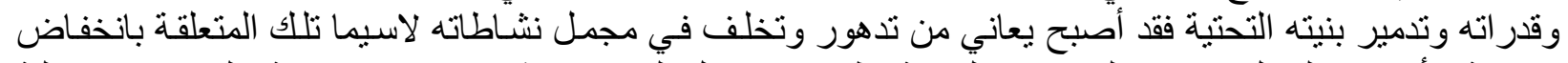

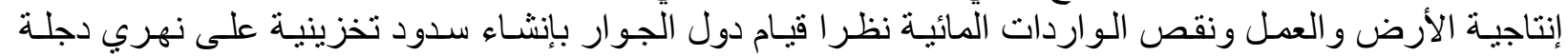

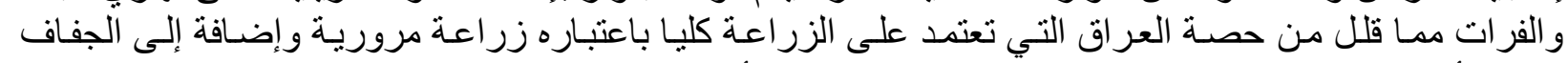

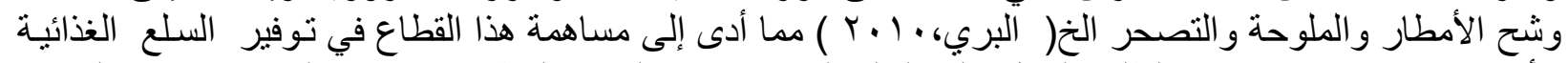

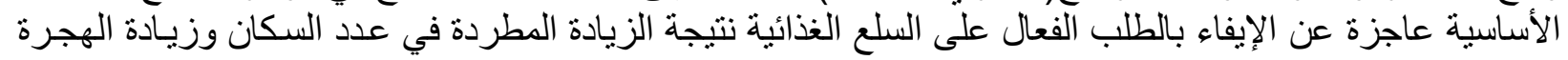

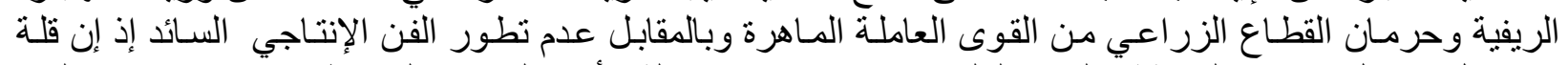

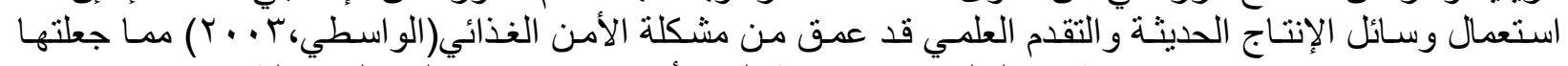

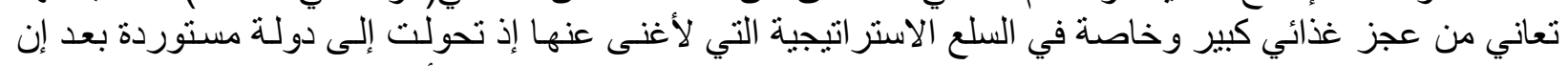

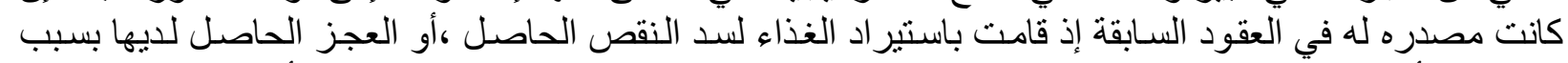

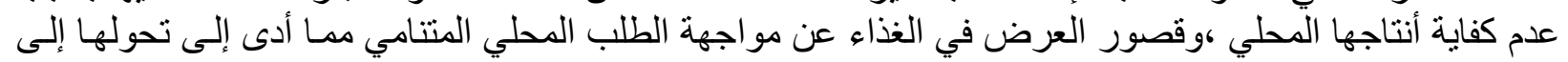

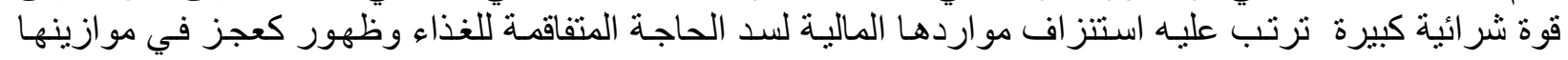

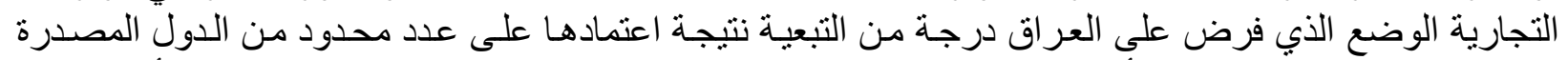

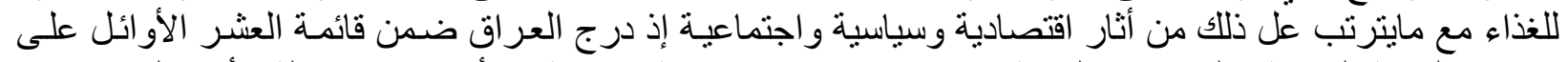

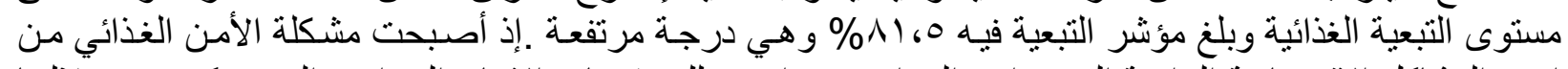

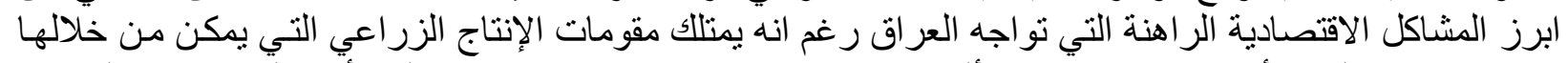

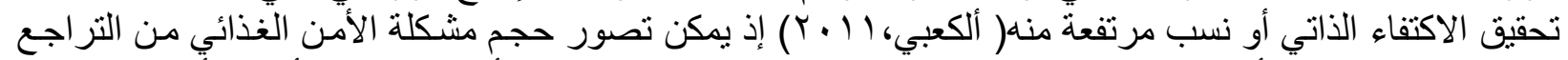

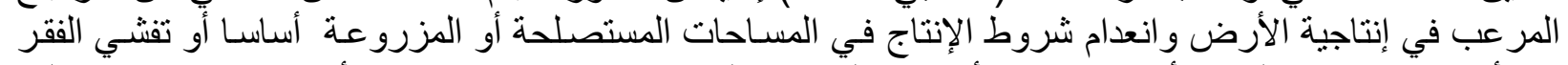

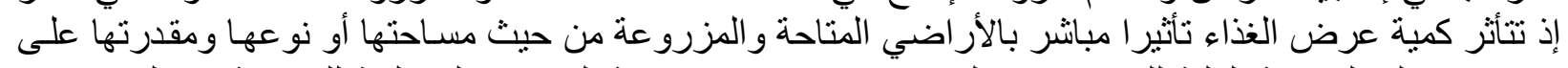

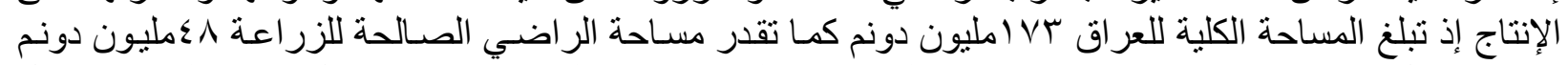

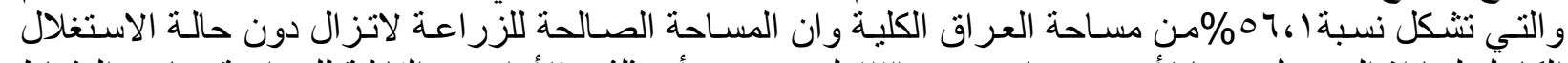

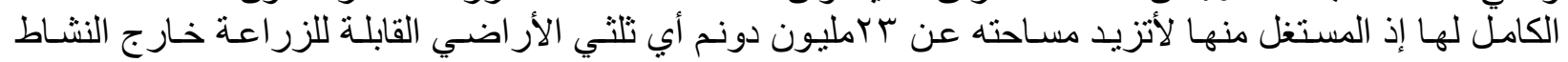

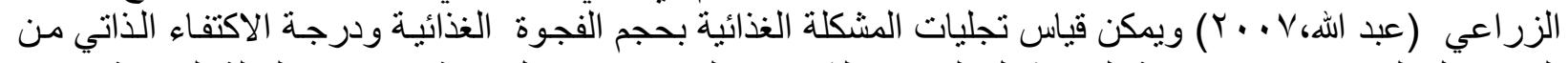

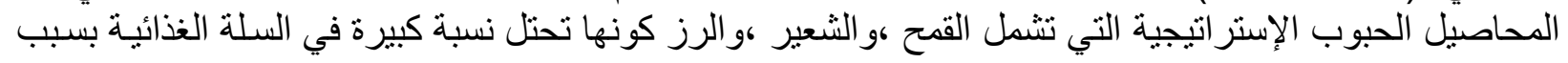


النمط الغذائي المتبع بالإضـافة إلى كونها ذات علاقـة وثيقة بـالأمن الغذائي إذ اخذ بعاني العراق من فجوة غذائيسة

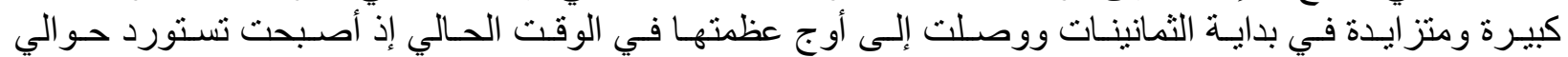

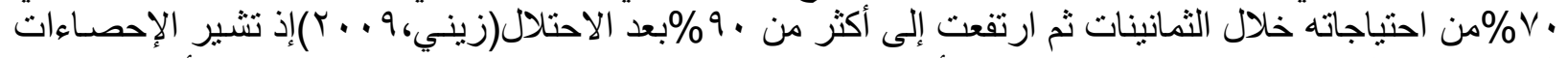

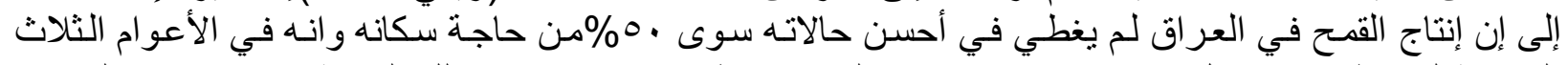

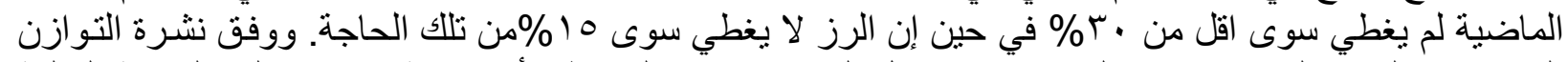

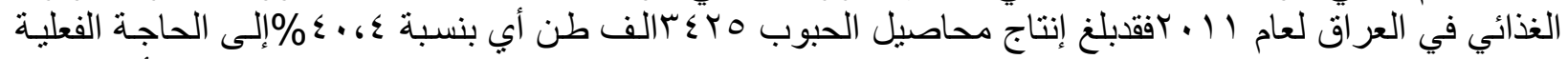

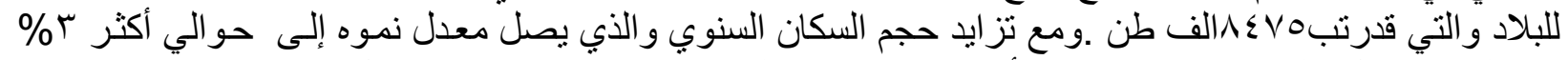

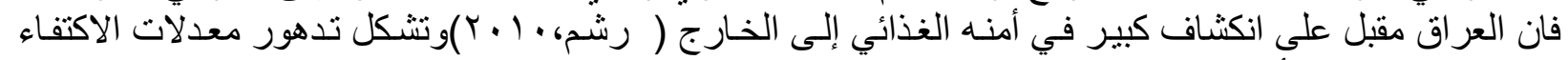

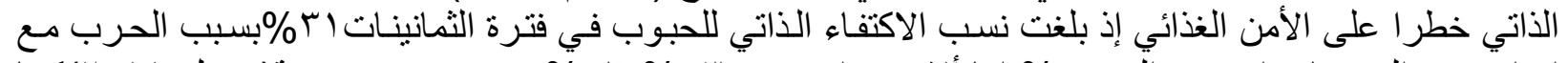

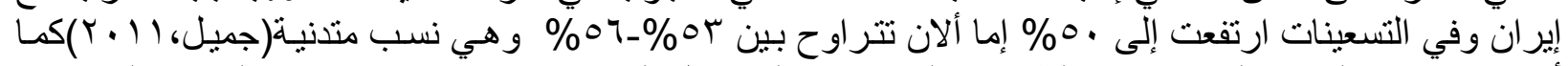

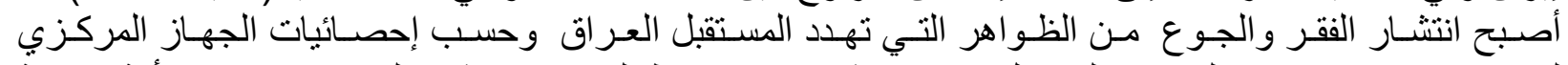

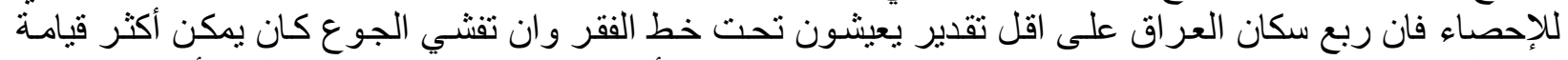

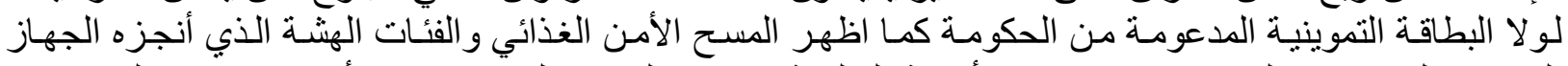

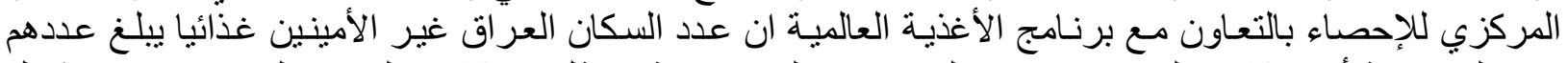

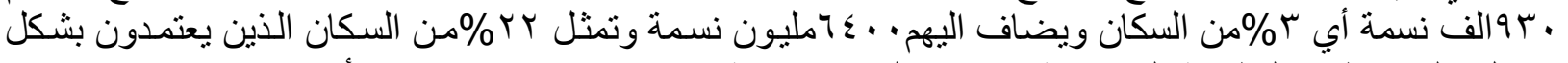

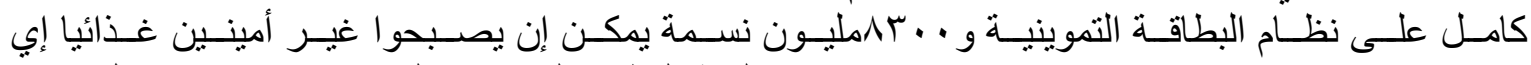

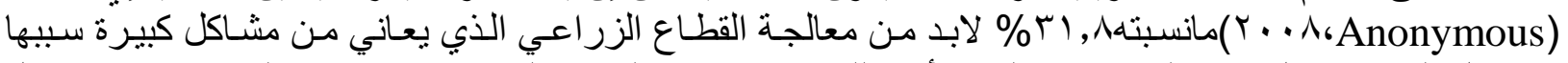

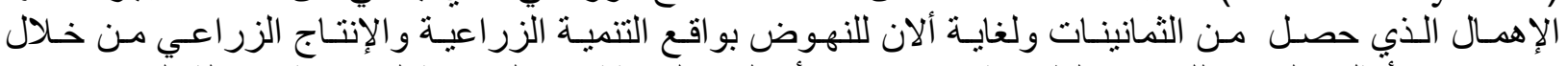

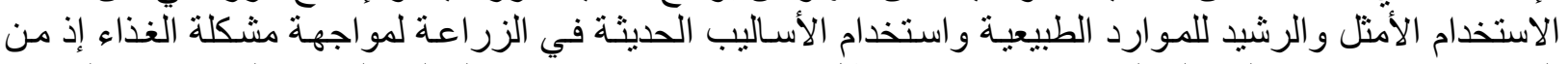

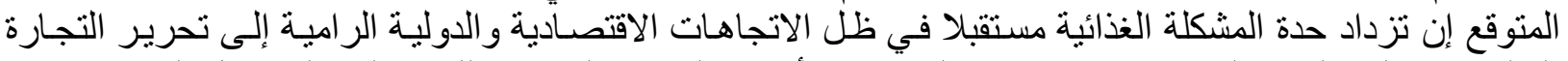

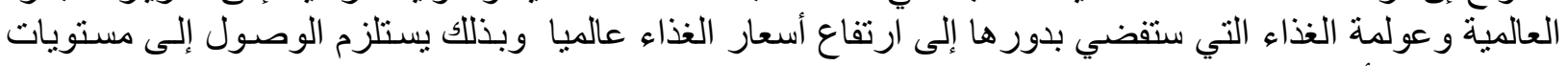
مرضية من الأمن الغذائي .

\section{مواد البحث وطر ائقه}

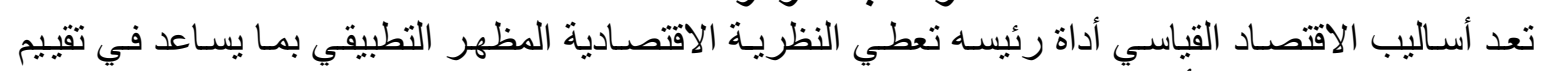

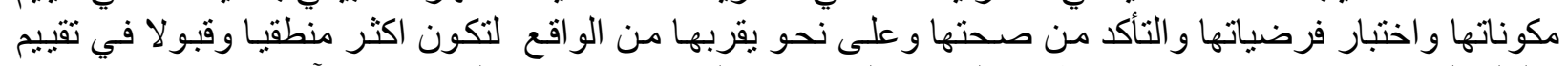

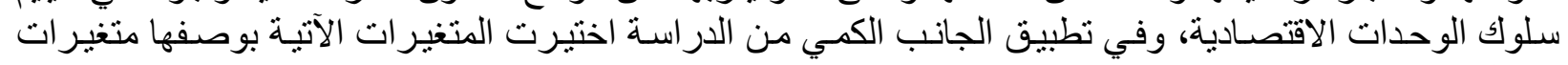

$\mathrm{Y}=\mathrm{F}(\mathrm{X} 1, \mathrm{X} 2, \mathrm{X} 3, \mathrm{X} 4, \mathrm{X} 5)$

$\mathrm{Y}=\mathrm{B} 0+\mathrm{B} 1 \mathrm{X} 1+\mathrm{B} 2 \mathrm{X} 2+\mathrm{B} 3 \mathrm{X} 3+\mathrm{B} 4 \mathrm{X} 4+\mathrm{B} 5 \mathrm{X} 5+\mathrm{UI})$

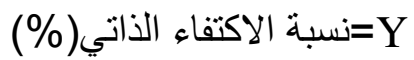

$$
\begin{aligned}
& \text { X1 } \\
& \text { =X2 } \\
& \text { X3 } \\
& \text { X4=حجم الطلب المحلي(ألف طن) X34 } \\
& \text { متوسط نصيب الفرد من الدخل(دولار) X5 } \\
& \text { B0 } \\
& \text { B1-B5 } \\
& \text { و=المتغير العشوائي }
\end{aligned}
$$

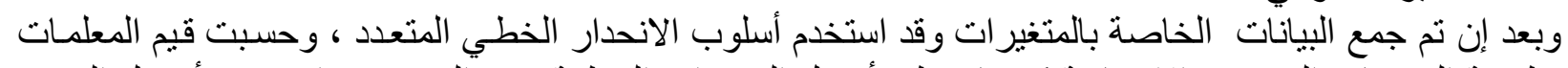

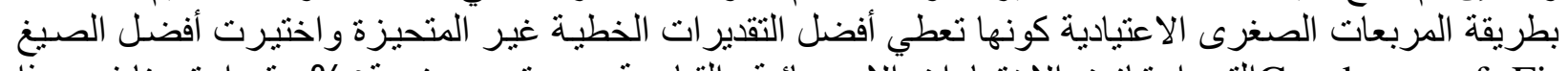
Goodness of Fit

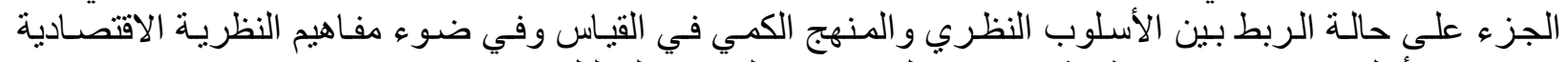
باستخدام الأسلوب الإحصائي ونظرية الاقتصاد القياسي في القيأس و التحليل. 


\section{النتائج والمناقشة}

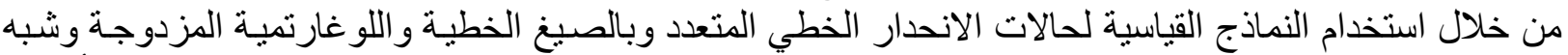

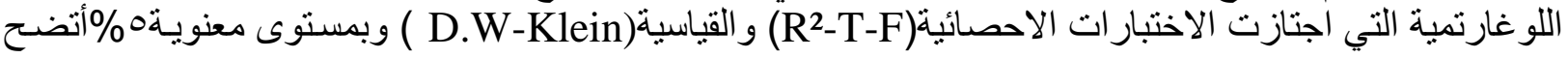

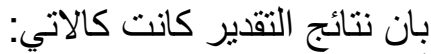

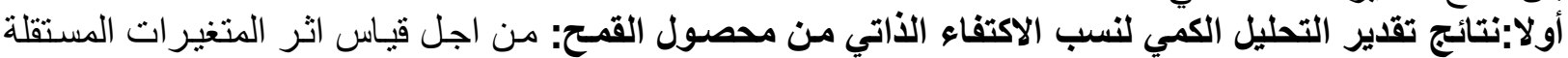

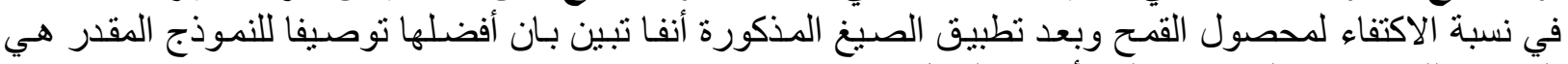
الصيغة اللوغارتمية المزدوجة التي أخذت الثنكل الاتي

Logy=1.15-0.309LogX1+0.130LogX2-0.251LogX3-0.292X4-0.178LogX5

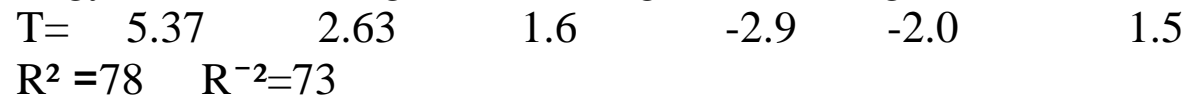

$\mathrm{F}=17.33$

D.W $=1.9$

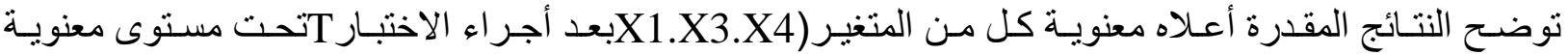

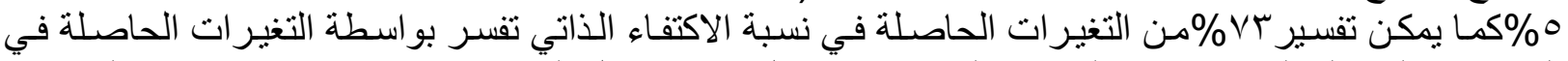

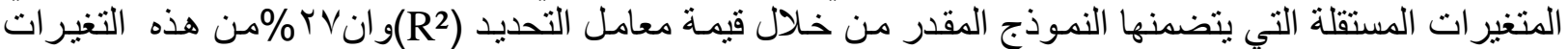

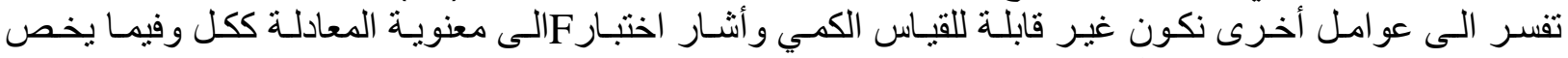

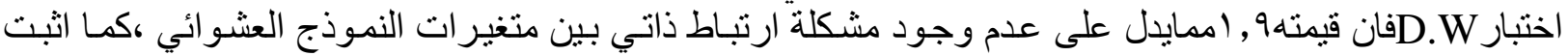

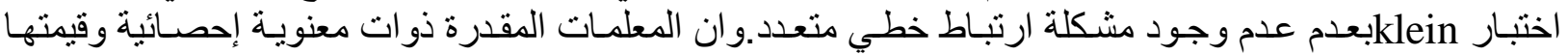

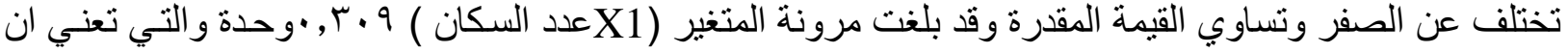

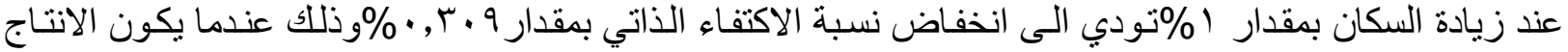

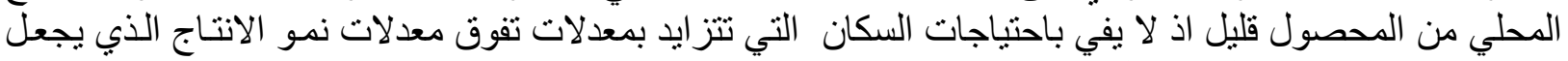

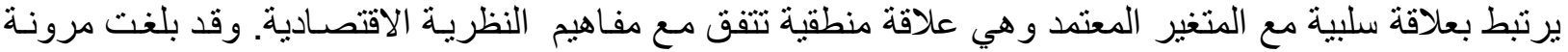

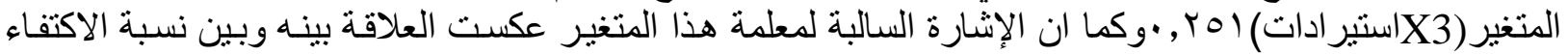

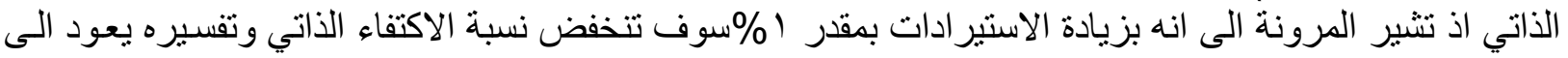

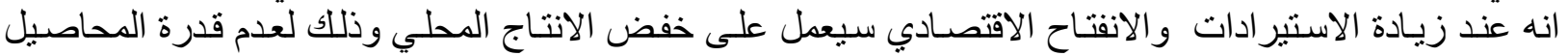

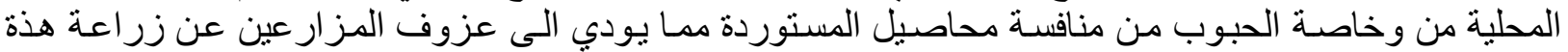

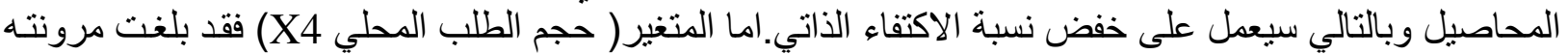

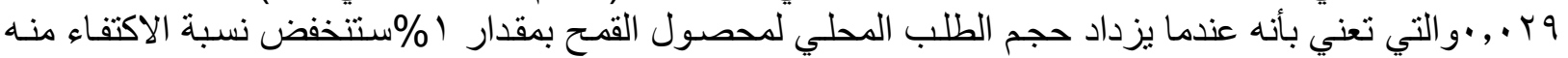

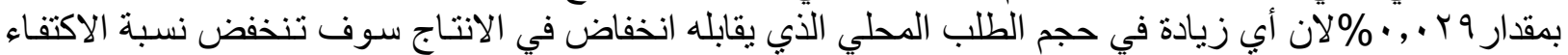

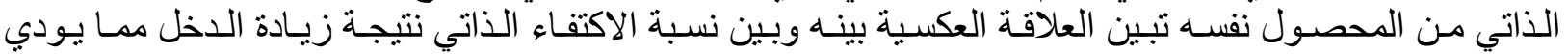

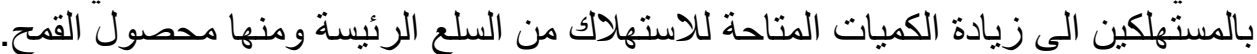

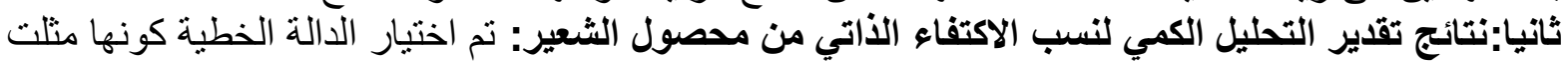

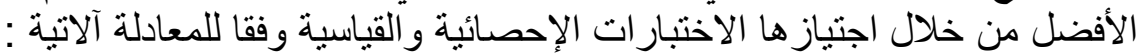
$Y=13.69+3.033 X 1+0.107 X 2-0.8 X 3-0.069 X 4-0.14 X 5$
$\mathrm{T}=0.48$
2.2
3.1
1.6
$-2.1$
$-1.9$

$\mathrm{R}^{2}=50.7$

$\mathrm{F}=13.91 \quad$ D. $\mathrm{W}=1.8$

توضح النتائج المقدرة أعلاه بعد إدخال جميع المتغيرات المتوقع تأثير هـا على نسبة الاكتفاء الذاتي من محصول

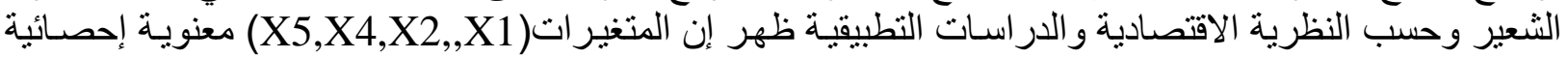

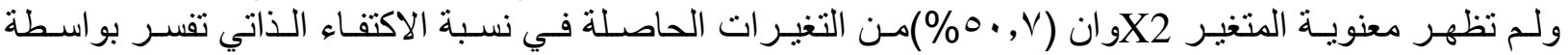

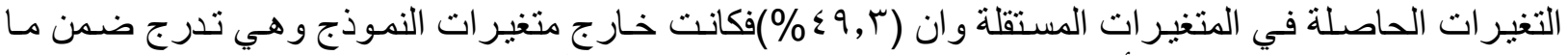

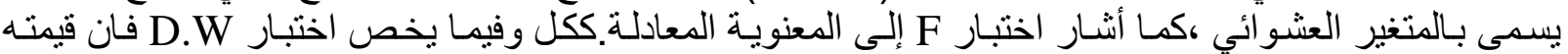

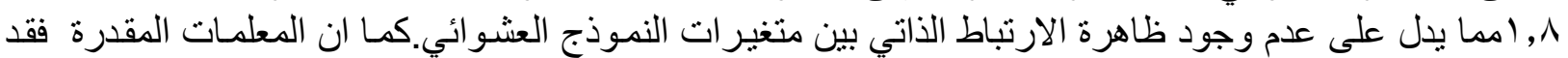

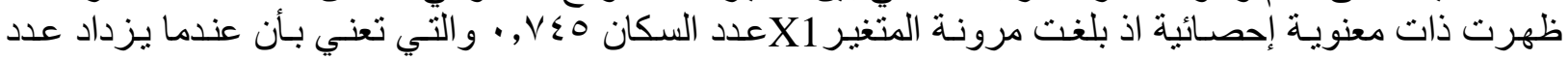

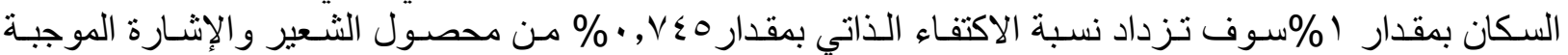

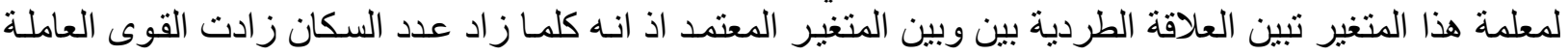

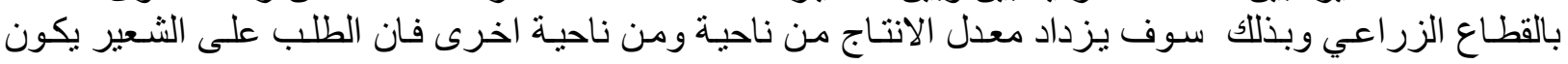




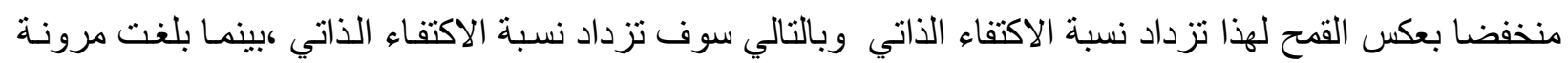

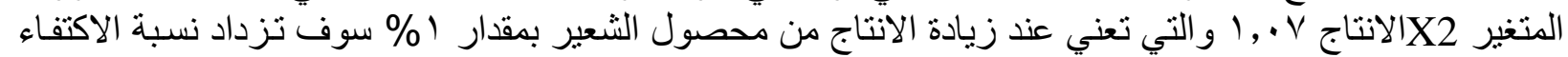

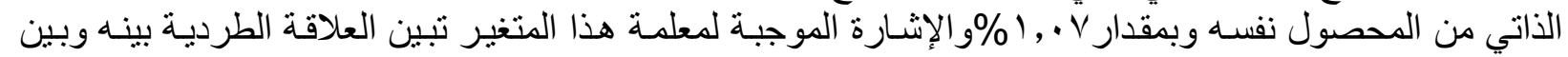

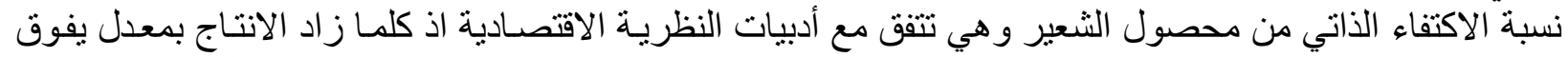

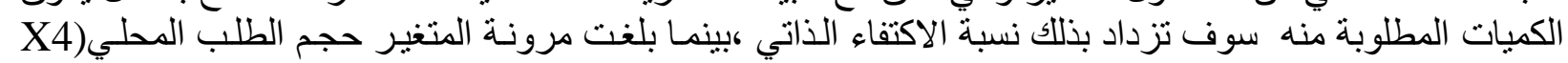

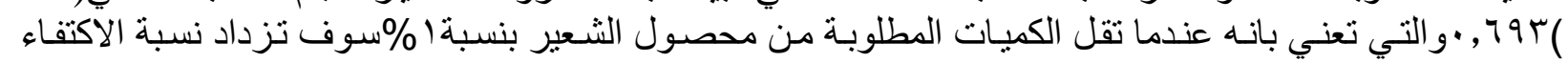

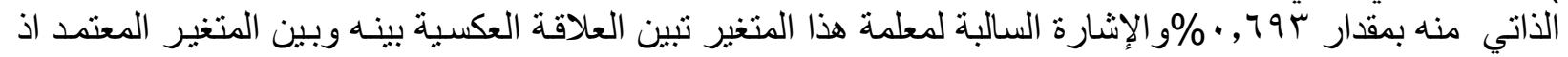

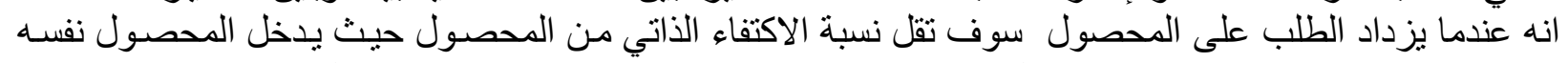

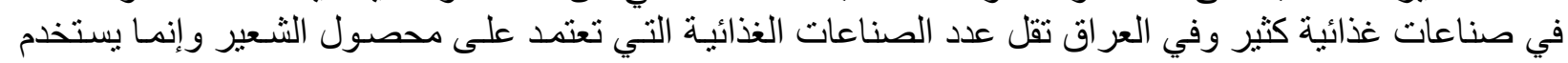

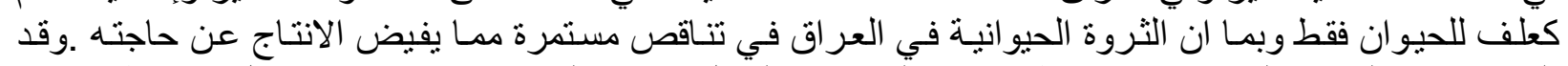

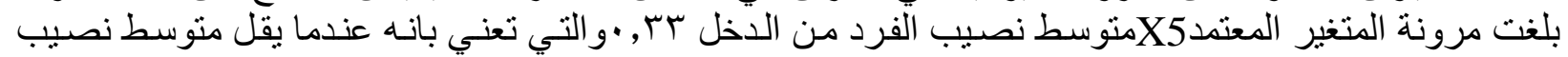

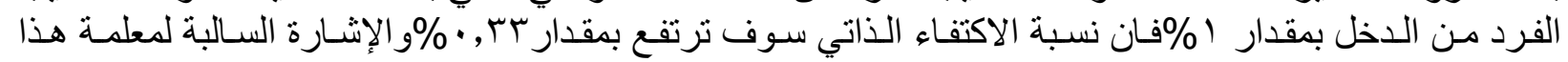

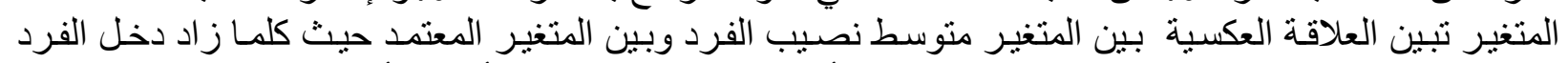

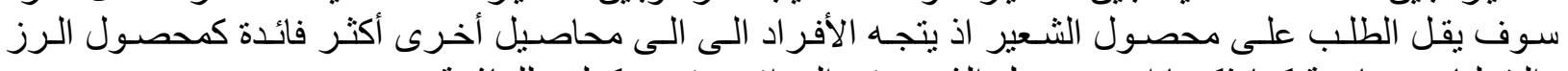

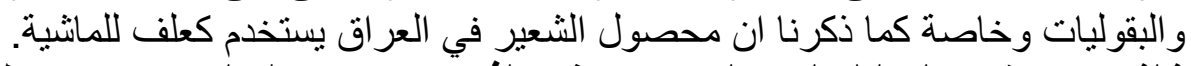

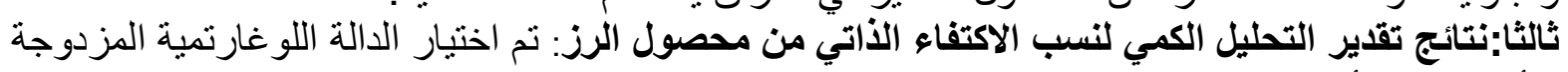

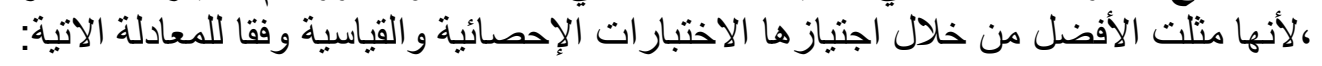
Logy=3.53-1.134LogX1+1.015LogX2+1.48LogX3-3.159LogX4 -0.369LogX5

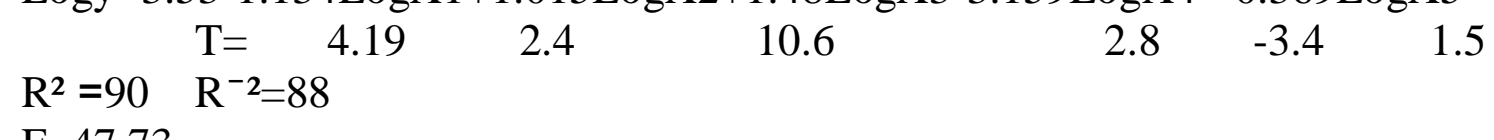

$\mathrm{F}=47.73$

D. $\mathrm{W}=2.39$

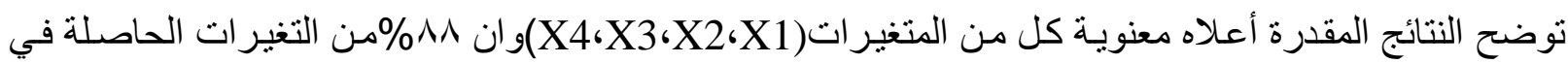

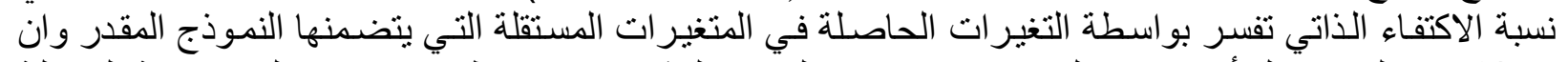

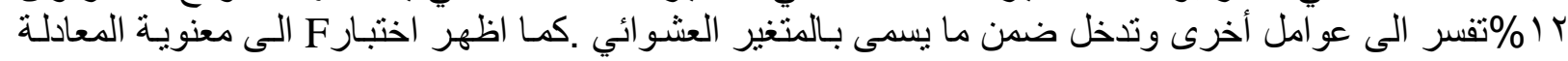

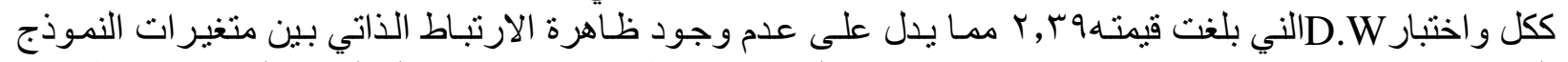

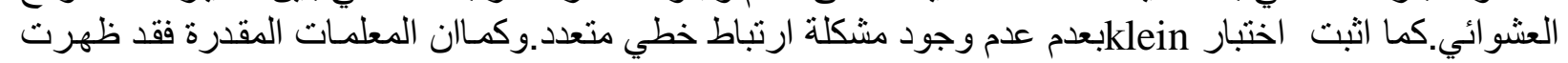

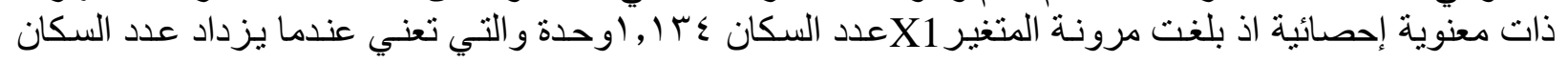

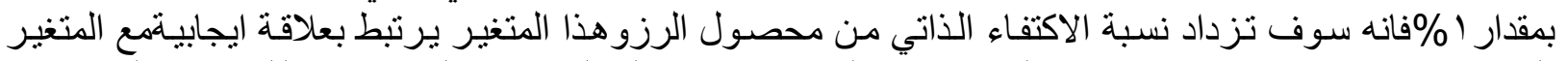

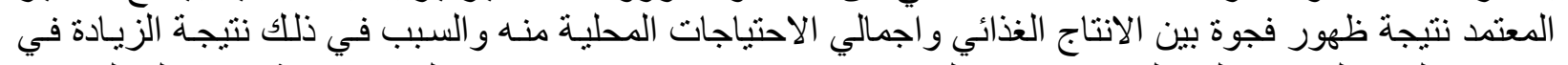

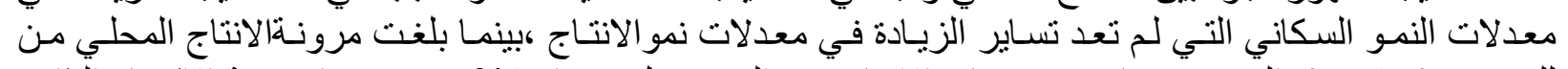

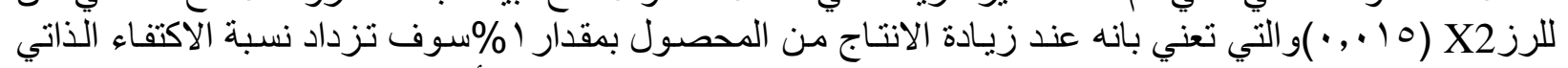

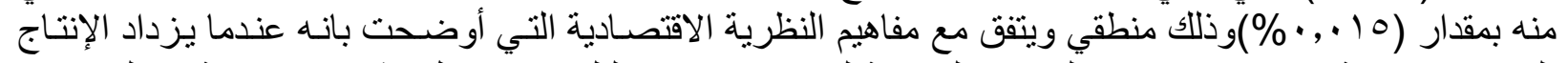

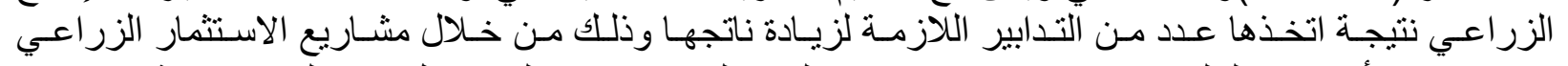

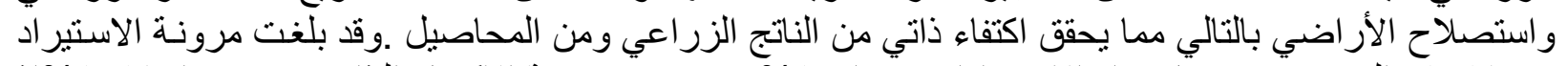

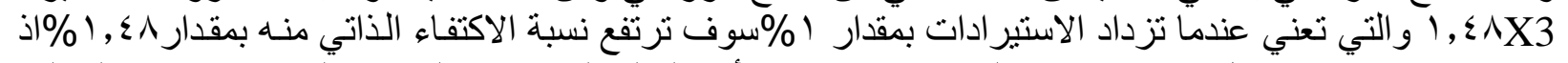

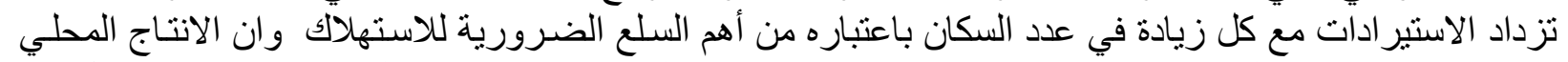

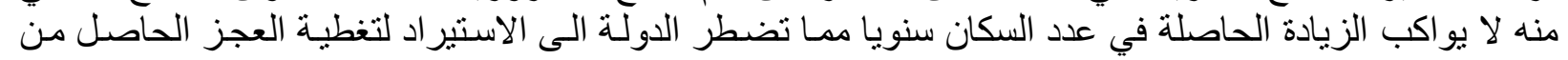

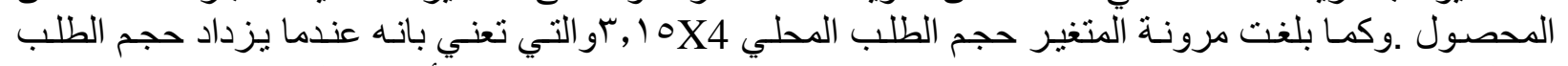

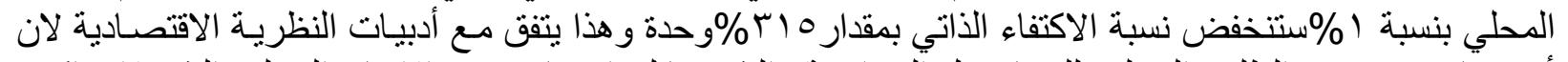

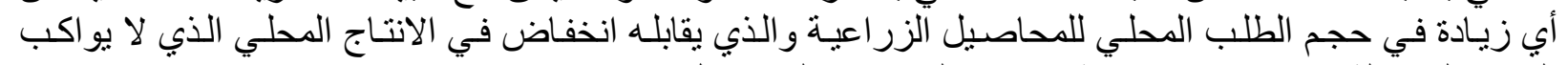

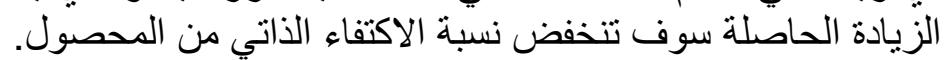

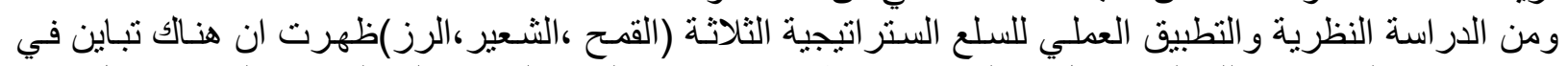

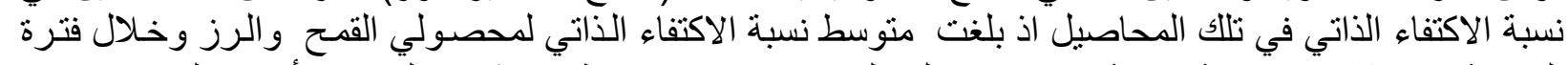

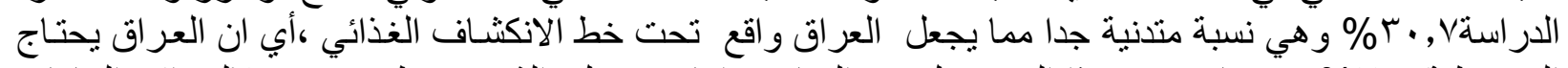

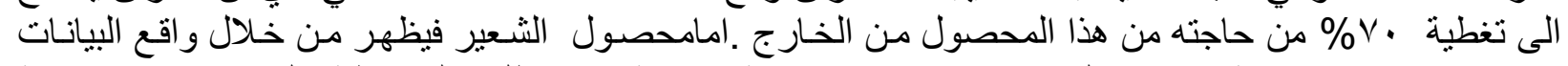

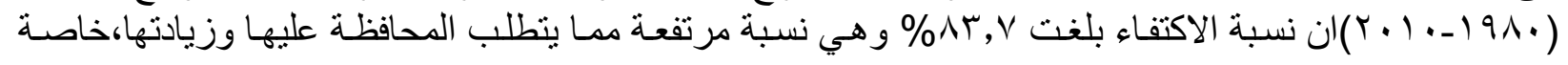




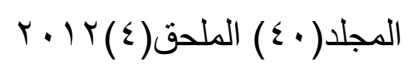

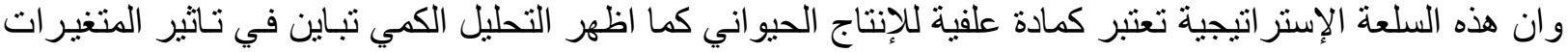

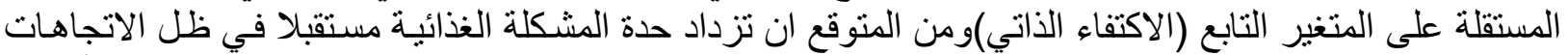

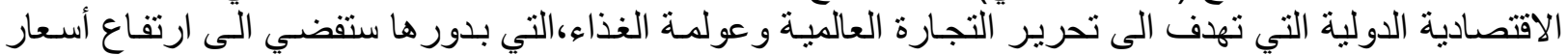

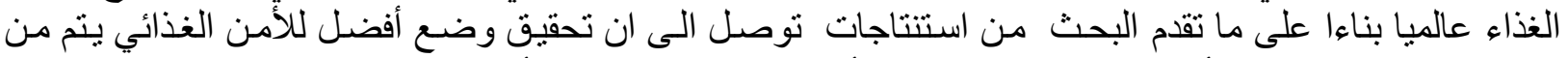

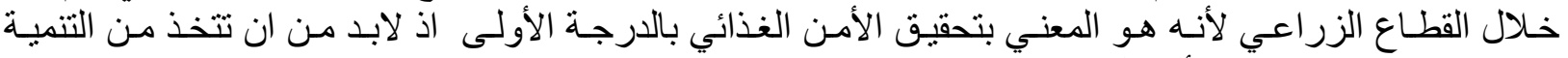

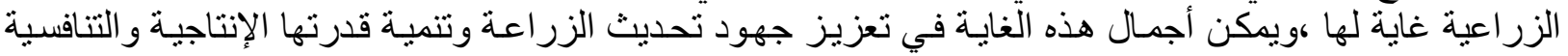

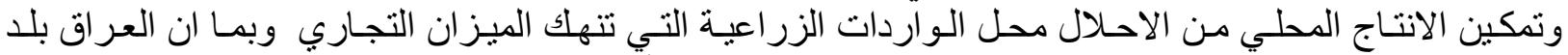

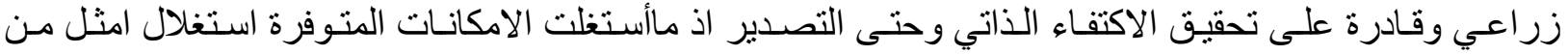

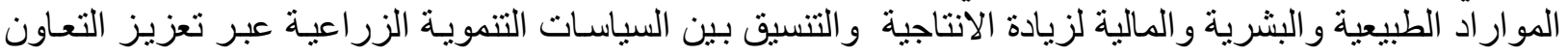

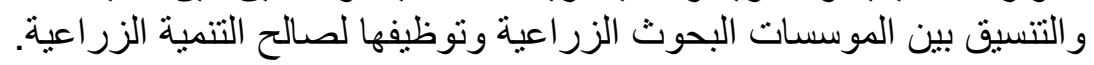

\title{
THE REALITY OF FOOD SECURITY IN IRAQ FOR THE PERIOD FROM (1980-2010)
}

\author{
Salim M, Salh \\ Muna A,Ahmed \\ Department of Agricultural Economics / College of Agriculture and Forestry / \\ University of Mosul - Iraq \\ SALIMS1956@yahoo.com Muna_agriculture@yahoo.com
}

\begin{abstract}
The research aims to study the concept of food security and Oaaqa food security in Iraq, the most important commodity strategy. Since become an issue of food security of the most important issues raised by the day where occupies utmost importance in light of the increasing population steady and lack of resources in light of the food crisis experienced by most countries, which were represented in decreased the most important food commodities major and growing demand and record highs in the price, and adopted research on the premise that food security in Iraq is moving towards increasing the gap between consumption of goods strategy and production of, and adopted research on the descriptive approach with quantitative analysis using multiple regression analysis. Where research has included time series range thirty years (1980 - 2010), and research found that there is variation in the proportion of self-sufficiency in crop strategy, amounting to the average self-sufficiency ratio for wheat and rice, during the study period $(30.7 \%)$ Amamahsol barley has reached self-sufficiency ratio $83.7 \%$ is expected that problem is particularly acute food future in light of international economic trends aimed at liberalizing global trade and globalization of food, which will lead in turn to rising food prices globally and increase the plight of the poor with her and requires access to satisfactory levels of food security and concerted efforts of the State in the development of integrated strategies food security for the advancement of the agricultural sector and agricultural production through optimal and rational use of natural resources and the use of modern methods of agriculture to address the proble of food.

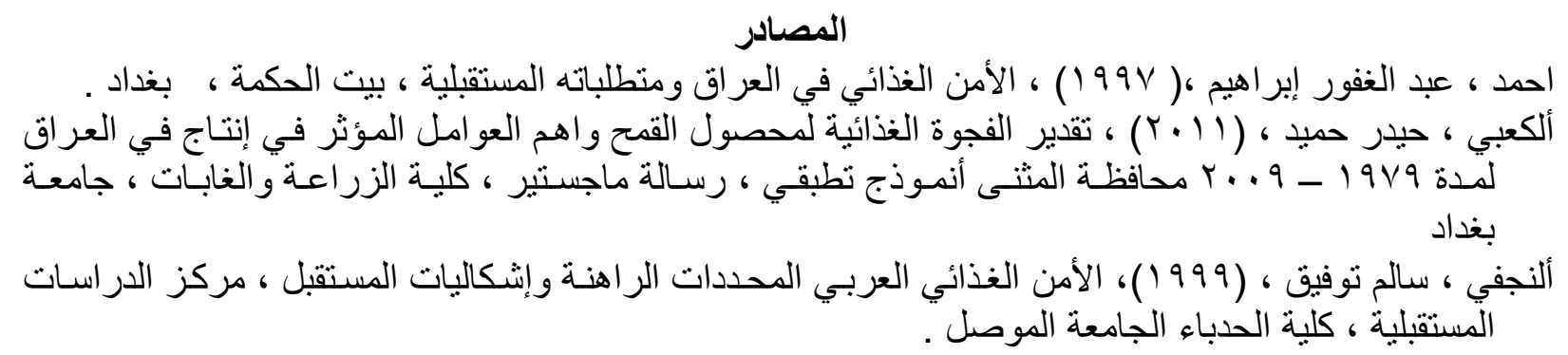




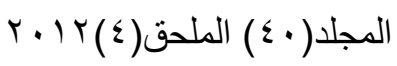
ISSN:2224-9796(Online)
ISSN: 1815-316X(Print)
مجلة زر اعة الر افدين

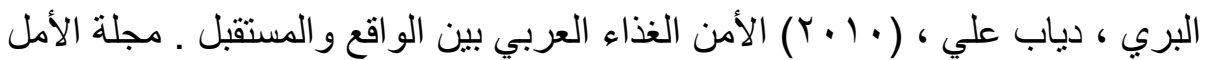

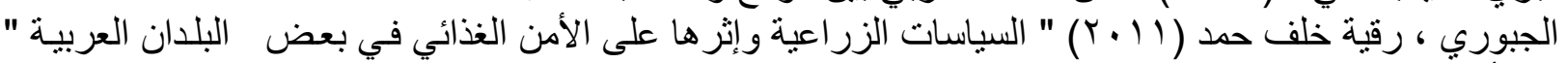

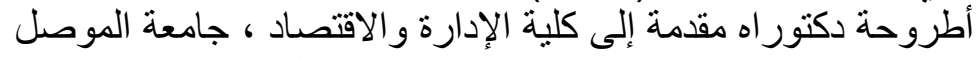

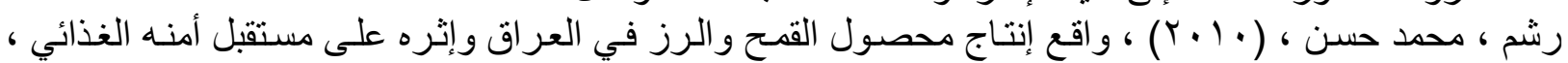

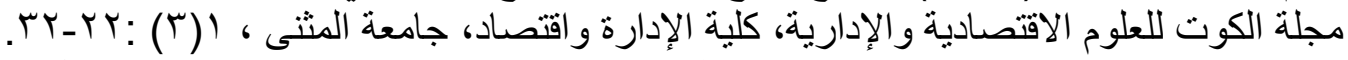

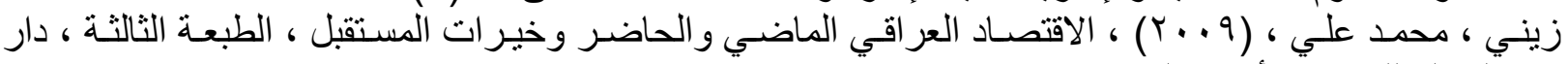

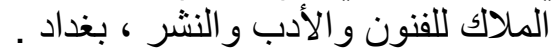

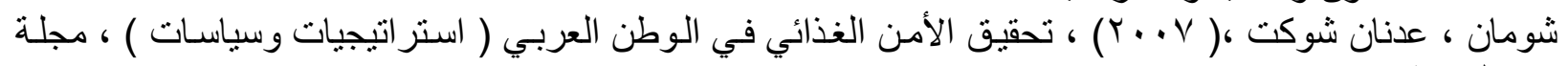

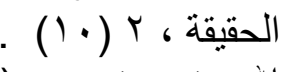

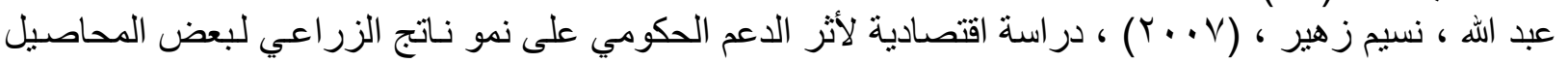

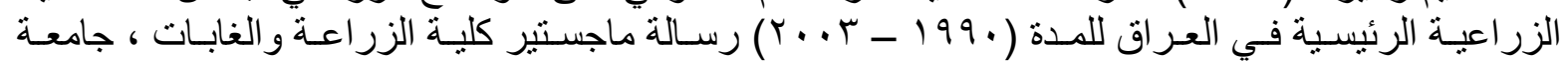

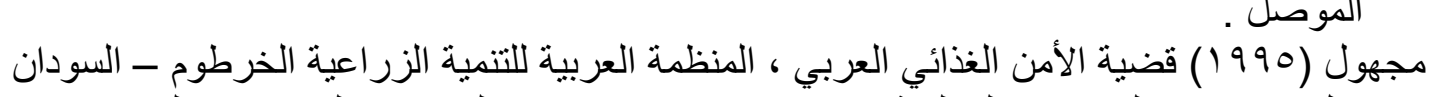

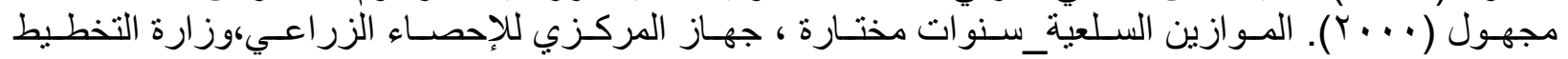
و التعاون الإنمائي.

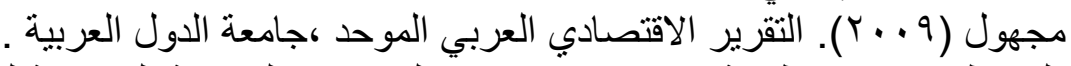

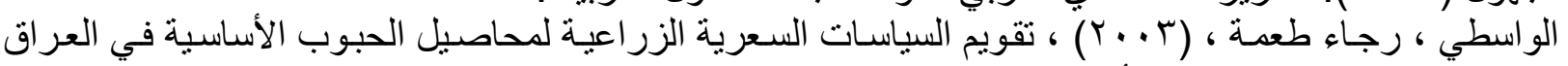

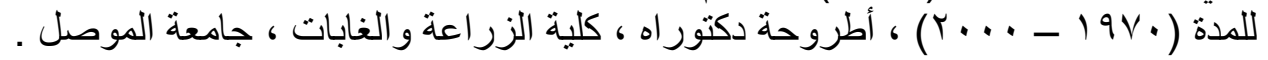
Anongmons,(2008),Comprehensive food security and vulnerability analysis in Iraq . 